\title{
Environmental effect on corrosion behavior of 9 MnSi5 steel pipelines
}

\author{
Aleksey Alkhimenko ${ }^{1 *}$, Boris Ermakov ${ }^{1}$, Ekaterina Alekseeva ${ }^{1}$, Artem Davidov $^{1}$, Mark \\ Kovalev $^{1}$, Svetlana Mushnikova ${ }^{2}$ \\ ${ }^{1}$ Peter the Great St. Petersburg Polytechnic University, National Technology Initiative Center for \\ Advanced Manufacturing Technologies, 194064 Saint-Petersburg, Russia \\ ${ }^{2}$ Central Research Institute of Structural Materials "Prometey”, 191015 Saint-Petersburg, Russia
}

\begin{abstract}
The increase in the corrosiveness of the produced fluid forces to reconsider the attitude towards the assessment of the serviceability and reliability of oil pipes, paying attention to the problems of increasing their corrosion resistance. The paper analyses environmental impact on pipeline made of $9 \mathrm{MnSi} 5$ steel after 12 months of operation in the oilfield to assess the residual life of pipeline and determine safe operating conditions. It was found that corrosion damage developed according to the mechanisms of general, pitting corrosion and stress corrosion cracking. Metallographic study has shown cracks of stress corrosion cracking that developed in environments containing carbon dioxide and hydrogen sulfide. Accelerated method of stress corrosion cracking resistance testing was implemented that allows to understand the tendency of steel to this type of cracking and gives a conclusion about the danger of brittle fracture of the pipeline.
\end{abstract}

\section{Introduction}

Modern oilfields are characterized by high corrosiveness of the produced fluid due to the presence of a significant amount of dissolved gases, abrasive particles, water cut, which can cause various types of corrosion damage, entailing serious economic and environmental consequences $[1,2]$.

The soluble salts, which are dissociated to a greater extent, chlorides, carbonates, bicarbonates and sulfates of sodium, magnesium, calcium have the highest corrosive activity in oil fluid [3]. The gas phase often contains a certain amount of carbon dioxide and hydrogen sulfide [4]. These gases, dissolving in the aqueous phase, have a strong corrosive effect on the walls of pipes and other metal equipment [5-9]. In addition, oil fluid always contains mechanical impurities in the form of sand, clay, rust and precipitated particles of mineral salts of magnesium and calcium, the solubility of which decreases with decreasing solution temperature [10].

Analysis of the increased accident rate of oil pipelines for various purposes showed [11-13] that corrosion cracking of pipes occupies one of the leading positions in the list of reasons for accelerated failure of pipelines in addition to the corrosion resistance of the metal and its quality $[14,15]$. Stress corrosion cracking in such media is not possible without the occurrence of

\footnotetext{
*Corresponding author: a.alkhimenko@spbstu.ru
} 
electrochemical reactions associated with the dissolution of the metal and the reduction of oxidants; therefore, the study of the electrochemical behavior of pipe steels is a necessary component of the study of corrosion cracking processes in the presence of $\mathrm{H}_{2} \mathrm{~S}$ and $\mathrm{CO}_{2}$.

At the facilities for the preparation and pumping of oil of the oil and gas field in the coils and pipelines, cases of damages were recorded due to reasons associated with brittle fracture in areas damaged by corrosion. Therefore in this work, the goal was to assess the residual life and safe operating parameters of oil pipeline made of $9 \mathrm{MnSi} 5$ steel after 12 month of operation. For this, the mechanisms of damage of this pipeline were investigated.

\section{Materials and methodology research}

For this study oil pipeline made of longitudinal welded pipes made of low carbon steel 9MnSi5 (P305) with a diameter of $720 \mathrm{~mm}$ and a wall thickness of $8 \mathrm{~mm}$ were investigated. Chemical composition of the steel is given in Table 1. After operation, the geometric characteristics of the damage and the residual pipe wall were evaluated.

Table 1. Chemical composition of studied steel

\begin{tabular}{|c|c|c|c|c|c|c|c|c|c|c|}
\hline \multirow{2}{*}{ Steel } & \multicolumn{10}{|c|}{ Mass., $\%$} \\
\hline & C & $\mathrm{Si}$ & $\mathrm{Mn}$ & $\mathrm{Cr}$ & $\mathrm{Ni}$ & $\mathrm{Cu}$ & $\mathrm{Al}$ & V & $\mathrm{S}$ & $\mathrm{P}$ \\
\hline $09 Г 2 C$ & 0,10 & 0.75 & 140 & 0.11 & 0.17 & 0.18 & 0.03 & 0.01 & $<0.03$ & $<0.03$ \\
\hline
\end{tabular}

A comprehensive study of the deposits formed on the surface after exploitation was carried out by methods of optical and electron scanning microscopy equipped with energy dispersive spectroscopy (EDS).

The tendency of steel to corrosion cracking (SCC) in environments saturated with $\mathrm{CO} 2$ and $\mathrm{H} 2 \mathrm{~S}$ was investigated by means of a slow strain rate technique (SSRT) based on testing specimens at a loading rate of no more than $5^{*} 10^{-6}-10^{-7} \mathrm{~s}^{-1}$, and allowing such tests quality that is not inferior to the results of static tests according to the NACE TM-0177 standard (method A). The method allows to determine the threshold stress $\left(\sigma_{1}\right)$ at which the metal does not undergo corrosion cracking, on a smaller number of samples and in a much shorter time than traditional static tests carried out according to the NACE TM 0177 method.

SSRT tests for the tendency to SCC were carried out on smooth cylindrical specimens with a working part diameter of $4 \mathrm{~mm}$ under axial tension with a relative strain rate of $110^{-6}$ $\mathrm{s}^{-1}$. One set of the samples were tested in the air, the second one in a $5 \%$ aqueous solution of sodium chloride, and the third - in a 5\% aqueous solution of sodium chloride with cathodic polarization at a potential of $-1.1 \mathrm{~V}$. In addition, the same tests were carried out according to the NACE TM 0177 method.

A modernized tensile testing machine with a maximum tensile force of $20 \mathrm{kN}$ was used as a loading device for testing the tendency to corrosion cracking. In parallel, 3 samples of each steel were tested, for which fracture diagrams were plotted in the coordinates "stress - strain".

\section{Results}

Figure 1 shows the results of scanning along the lower generatrix of the inner surface of a pipe made of $9 \mathrm{MnSi} 5 \mathrm{steel}$ after 12 months of operation. The initial pipe thickness in the places not exposed to corrosion was $8.00 \pm 0.50 \mathrm{~mm}$. The service life of the pipe until the moment of research is 12 month. 


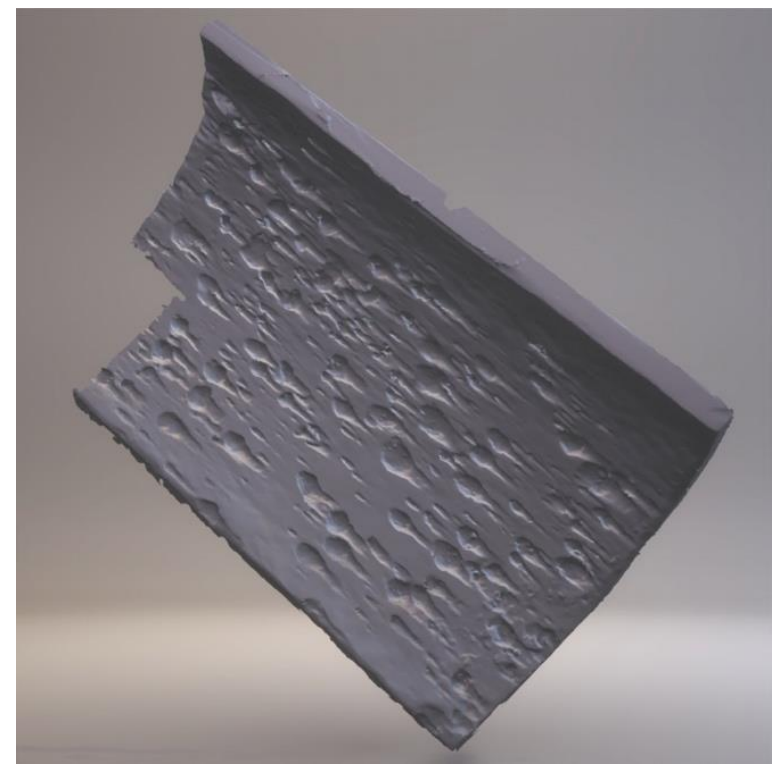

Fig. 1. Result of the scanning of internal surface of 09G2C pipe.

The study shows that the main corrosion processes take place in the lower 1 part of oil pipelines that corrosion is observed. It was determined that the maximum depth of the corrosion damage reaches $4 \mathrm{~mm}$, the degree of local lesions is up to $67 \%$ of the surface of the studied fragment and up to $50 \%$ of the wall thickness (at a height of no more than $1 / 3$ of its diameter). The average corrosion rate, based on a 12-month service life, is $\sim 0.85 \mathrm{~mm} /$ year. The local corrosion rate is more than $4 \mathrm{~mm} /$ year.

The analysis of the corrosion products showed that the outer layer of corrosive damage is characterized by a thin dense uniform distribution of corrosion products (over the surface and pits) of dark brown color. Analysis of the corrosion products (Fig. 2, Table 2) shows iron, carbon and oxygen, the weight ratio of which is close to the chemical compound of the composition of iron carbonate $\left(\mathrm{FeCO}_{3}\right)$. An increased sulfur content was also revealed. The formation of salt deposits of this type in corrosion products can be explained by the passage of a corrosion reaction in the presence of carbon dioxide and hydrogen sulfide in the operating environment.

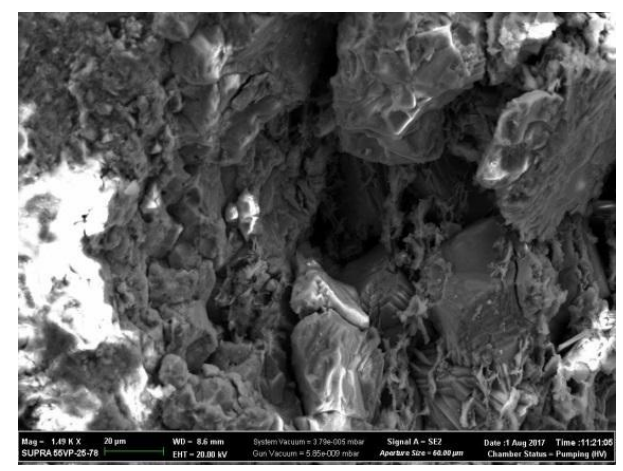

Fig. 2. General of corrosion products after operation in oilfield

Table 2. Analysis of corrosion products on the sample surface

\begin{tabular}{|l|l|l|l|l|l|l|l|l|l|l|}
\hline Element & $\mathrm{C}$ & $\mathrm{O}$ & $\mathrm{P}$ & $\mathrm{S}$ & $\mathrm{Cl}$ & $\mathrm{Ca}$ & $\mathrm{Fe}$ & $\mathrm{Mn}$ & $\mathrm{Al}$ & $\mathrm{Ni}$ \\
\hline mass. $\%$ & 21.85 & 56.26 & 0.07 & 1.73 & 0.03 & 1.22 & 17.90 & 0.28 & 0.15 & 0.30 \\
\hline
\end{tabular}


Metallographic analysis of the metal on the samples revealed not only traces of general and pitting corrosion but also revealed crack-like defects developing almost perpendicularly from the inner surface of the pipe, fig. 3. The depth of the defects was in the range from 100 to 250 $\mu \mathrm{m}$. Such cracks are typical for corrosion cracking of steels in environments saturated with carbon dioxide and hydrogen sulfide. The possibility of the presence of these gases in the pumped fluid was determined by analysis of the corrosion product composition.

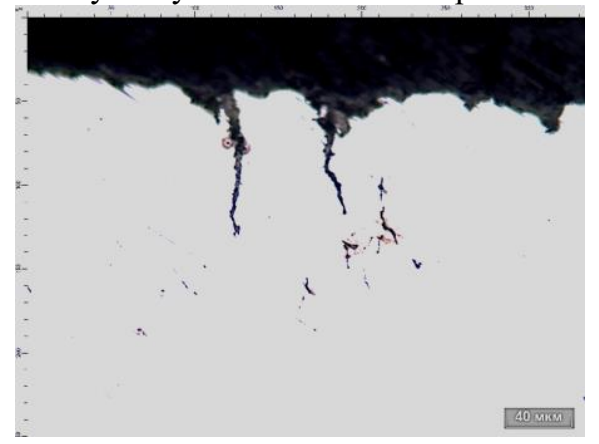

Fig. 3. Traces of general and pitting corrosion (a) and crack-like defects on the inner surface of the metal of cuttings from pipes (b).

Thus, based on the analysis of damaged pipe sections, three types of corrosion damage mechanisms were identified. These are general corrosion, pitting corrosion and stress corrosion cracking (SCC) in environments containing carbon dioxide and hydrogen sulfide. It is SCC that, in this case, is the most dangerous aggressive effect and can lead to high-speed destruction. Therefore, the main attention was paid to the study of this type of destruction.

According to the recommendations of the NACE MR 0175 standard for SCC testing, for this class of steels it is necessary to apply a static load of no more than $70 \% 6_{0.2}$. During static tests, it was found that 09GSF steel samples did not withstand the test conditions according to the NACE TM 0177 method and were destroyed in less than 720 hours, therefore additional static tests were carried out at applied stresses $65 \% 6_{0.2}$ (ahead of schedule destruction). At $60 \% 6_{0.2}$ samples were specimens passed 720 hours of testing without cracking, table 3 .

Table 3. Test results for susceptibility to stress corrosion cracking

\begin{tabular}{|c|c|c|c|c|c|}
\hline \multicolumn{3}{|c|}{ SSC, NACE TM 0177 } & \multicolumn{3}{c|}{ Accelerated SSRT method } \\
\hline$\% \sigma_{0.2}$ & Time, $\mathrm{h}$ & $\sigma_{1,} \mathrm{MPa}$, & $\sigma_{1},\left(\% \sigma_{0.2}\right)$ & Time, $\mathrm{h}$ & $\sigma_{1}, \mathrm{MPa}$ \\
\hline 70 & 107 & 348 & 63 & 41 & 355 \\
65 & 514 & & & & \\
60 & 720 & & & & \\
\hline
\end{tabular}

As follows from the data in Table 2, the results of tests carried out by both methods showed a good convergence of results - the threshold stress by NACE 0177 is $348 \mathrm{MPa}$ and $355 \mathrm{MPa}$ with accelerated method, however, the time spent on accelerated tests was 41 hours, and according to the NACE TM $0177107+514+720$ hours, i.e. 1341 hours. The data obtained make it possible to recommend the pipes used at the operating pressure of the medium not exceeding $60 \%$ of the yield point, which will guarantee the equipment protection against the occurrence of metal corrosion cracking.

Thus, having received data on the corrosion rate of the pipe metal, the level of stresses at which cracks in the SCC can occur, it seems possible to assess both the residual life of an existing oil pipeline and to predict the operability of a new pipeline instead of damaged by corrosion of an existing one. 


\section{Conclusions}

1. It is shown that under conditions of aggressive action of the produced fluid, the material of pipes made of steel $9 \mathrm{MnSi}$ is subjected to corrosion by three types of mechanisms general corrosion, pitting corrosion and corrosion cracking in environments saturated with carbon dioxide and hydrogen sulfide.

2. The corrosion rate in the in-pipe space is not the same - the most corroded pipe sections are located along the lower part of the pipe. The rate of metal corrosion along the lower generatrix of the pipe in this case reaches more than $4 \mathrm{~mm}$ per year. Corrosion products containing a significant amount of carbon and sulfur, as well as the results of metallographic analysis, revealed the presence of brittle stress corrosion cracking cracks, the depth of which was in the range of 100-250 microns, further reducing the actual pipe wall thickness.

3. Considering that it is SCC in environments saturated with carbon dioxide and hydrogen sulphide that is the most important and difficult to control factor regulating the safe operation of the pipeline, tests of the cut metal for its tendency to $\mathrm{CC}$ were carried out in the work. According to the test results according to the proposed method, confirmed by the results of static tests NACE TM 0177, it was found that $9 \mathrm{MnSi} 5$ steel does not exhibit a tendency to stress corrosion cracking at stresses not exceeding 60 (63\%) of the yield strength. Such data made it possible (with measurements of the actual pipe thickness) to clarify the safe operating parameters of the existing pipeline, and knowing the rate of wall thinning under the influence of other corrosive factors, to determine the period of its safe operation.

\section{References}

1. V. V. Kuznetsov, A. A. Lyapin, R. E. Monakhov, Gas and Business. 1-2, 49-56 (2007)

2. A. P. Medvedev, Markin A. N. Oil field agriculture. 11 56-59 (1995).

3. A.A. Gonik Corrosion of oilfield equipment and measures of preventing it,192 (1976)

4. A.N. Markin, R.E. Nizamov, CO2-Corrosion of oilfield equipment. JSC "VNIIOENG» (2003)

5. I. Kostitsyna, A. Shakhmatov, A. Davydov, E3S Web Conf., 121 04006, (2019)

6. V.G. Antonov, A.B. Arabey, V.N. Voronin et al. Stress corrosion cracking of main pipelines. Atlas. (2006)

7. R. Chu, W. Chen, S.H. Wang et al. Corrosion. 60 275-283 (2004)

8. M.M. Kantor, V.V. Sudin, K.A. Solntsev, Inorganic Materials 55 409-416 (2019)

9. Vyboishchik, M.A., Ioffe, A.V., Kudashov, D.V., Fedotova, A.V., Mironova, Y.V. Russian Metallurgy (Metally), 10 1171-1176 (2020)

10. I. M. Muravyev, R. S. Andriasov. Development and operation of oil and gas fields. 445 (1970)

11. Zelenin A. A. Engineering practice 9 4-6 (2016)

12. Vyboishchik, M.A., Ioffe, A.V., Tetyueva, T.V. et. Al. Russian Metallurgy (Metally), 10 1162-1170 (2020)

13. V. M. Kushnarenko, V. S. Repyakh, E. V. Kushnarenko, E. Y. Chirkov, Vestnik OSU. $11610153-159$ (2010)

14. I. G. Rodionova, O. N. Baklanova, A. I. Zaytsev, Metals. 2 362-367 (2004).

15. I.G., Rodionova, O.N.Baklanova, G.A .Filippov et.al., Metallurgist. 4 125-130 (2005) 